\title{
A COMPARATIVE ASSESSMENT OF DIFFERENT OPTIONS TO REDUCE $\mathrm{CO}_{2}$ EMISSIONS
}

\author{
Sabine Messner and Nebojక̌a Nakićenović \\ International Institute for Applied Systems Analysis (IIASA) \\ A-2361 Laxenburg, Austria
}

\begin{abstract}
The IIASA research project on Environmentally Compatible Energy Strategies includes the assessment of options and measures for mitigating global $\mathrm{CO}_{2}$ emissions. The basis of this assessment is the comparative inventory of technological and economic measures including efficiency improvement, conservation, enhanced use of low-carbon fuels, carbon free sources of energy and measures for removing carbon from fuels, flue gases and also from the atmosphere such as afforestation, and finally also measures for enhancement of carbon sinks. To include all potential options, the comparison is based on energy end-use accounting for the fully interlinked energy conversion chain up to energy resources. The analysis is supported by a fully interactive data bank system, CO2DB, that is capable of evaluating full energy chains with respect to their economic, technical and environmental parameters. The paper reports energy requirements, cost and $\mathrm{CO}_{2}$ emissions for different energy chains providing industrial drives, cooling and air transport services. At additional cost, emissions can be reduced drastically on all these end-use categories.
\end{abstract}

\section{KEYWORDS}

Energy chains, $\mathrm{CO}_{2}$ reduction and removal, $\mathrm{CO}_{2}$ emissions, mitigation data base, energy efficiency, technologies, costs.

\section{CARBON DIOXIDE AND GLOBAL ENERGY}

The current carbon dioxide content of the atmosphere is about 760 Gigatons (Gt) of carbon compared with annual emissions of about $6 \mathrm{Gt}$ of carbon from fossil energy use. The atmospheric carbon content is less than four times the cumulative global emissions from fossil energy use of about $200 \mathrm{Gt}$ of carbon. This illustrates the massive interference in the global carbon cycle. Compared to the historical carbon releases, the remaining "carbon endowment" accumulated over geological times in form of fossil energy deposits is orders of magnitude larger. The economically recoverable energy reserves amount to $540 \mathrm{Gt}$ of carbon and thus almost equal the total carbon in the atmosphere (see Grübler and Nakicenovic, 1991). Additional $3000 \mathrm{Gt}$ of carbon are in the form of estimated resources (i.e., identified quantities with uncertain prospects for economic recoverability) and $5000 \mathrm{Gt}$ of carbon are estimated in additional occurrences (inferred quantities with largely speculative technical and economic potentials). This clearly shows that even the currently known fossil energy resources, if ever consumed, would be sufficiently large to raise the atmospheric carbon dioxide concentrations beyond environmentally acceptable levels. Thus, future energy policies must be based on precautionary principles by limiting 
and even reducing emissions of greenhouse gases. Consequently, a number of national carbon dioxide $\left(\mathrm{CO}_{2}\right)$ reduction plans have been announced, aiming to stabilize and in some cases even reduce further emissions.

\section{ENERGY AND THE ENVIRONMENT}

The research project on Environmentally Compatible Energy Strategies at the International Institute for Applied Systems Analysis (IIASA) focuses on formulating long-term options and strategies for environmentally compatible energy development. In particular, the objective is to assess future potentials and rates of reducing energy and carbon intensity worldwide. Figure 1 shows historical improvements toward reducing carbon intensity in a number of selected countries. The aim is to analyze future trajectories that would lead individual countries and the world as a whole further toward lower specific emissions per unit value added as shown for the historical changes in Figure 1 . At similar levels of affluence, some countries emit less and other more carbon indicating that decarbonization and development are not mutually exclusive provided an appropriate policy mix is found. Especially striking is the large "North-South" disparity in energy-related carbon emissions. Current per capita carbon emissions differ by nearly a factor of 9 (on average 3.3 tons of carbon per capita in the more developed countries compared with 0.4 tons in developing countries). The burden of the developing countries is two-fold. They both need to increase their per capita energy consumption in order to improve the quality of life and are also more vulnerable to adverse consequences of climate change. While industrialized countries are in a better position to achieve emissions reductions they are also in a better situation to respond and adapt to climate change.

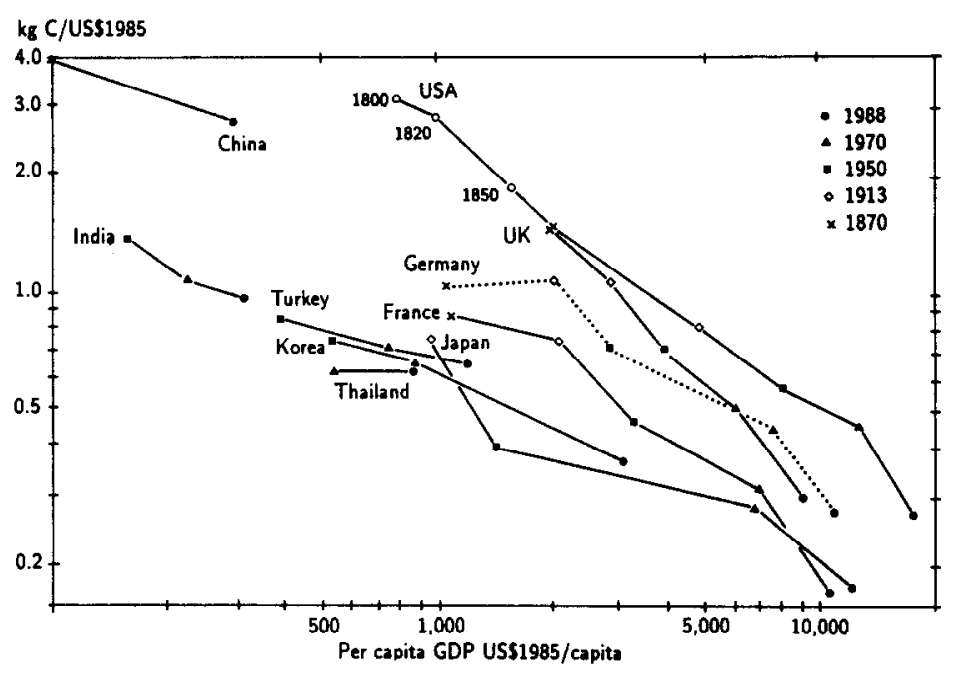

Fig. 1. Energy $\mathrm{CO}_{2}$ emissions intensity per constant GDP, in $\mathrm{kg}$ carbon per constant 1985 US\$ versus per capita GDP in constant 1985 US\$ (Grübler and Fujii, 1991).

These considerations suggest that in the absence of appropriate countermeasures global emissions of greenhouse gases will continue to increase well into the 21 st century, perhaps beyond environmentally acceptable levels. A comparative assessment of different options and strategies for mitigating and adapting to possible global warming is therefore required. The main part of the research project at IIASA focuses on a comprehensive assessment of a broad range of options (technologies, associated economic incentives and institutional frameworks for their implementation) that is needed for evaluating the global potential for stabilizing, ultimately reducing and perhaps even removing carbon dioxide and other greenhouse gases from the atmosphere (see also Nakicenovic and John, 1991). This research effort involves the development of an inventory of technologies for reducing carbon dioxide emissions. This inventory will provide information about technical characteristics of technologies, their cost structure and economies, and environmental profiles such as specific emissions. An important feature of this 
inventory is that it will also specify the applicability of mitigation technologies in different technological, economic or cultural settings, and will specify the time horizon of their availability and their forward and backward linkages to other enabling technologies in the energy system.

\section{INVENTORY OF MITIGATION MEASURES}

The technological and economic measures to minimize energy-related GHGs emissions include efficiency improvements, conservation, enhanced use of low-carbon fuels, carbon free sources of energy and other options such as afforestation, enhancement of natural carbon sinks and creation of new ones. Thus, they encompass the whole energy system from primary energy to actual energy use including various conversion, transport, distribution and end-use systems. This is important for assessing the overall mitigation potential and possibilities. For example, energy end-use is the least efficient part of current energy systems so that it becomes of crucial importance to include end-use technologies that provide transport, industrial or residential energy needs into the mitigation assessment. A detailed assessment shows that the global conversion efficiency from primary energy to final energy forms is about 74 percent (Nakićenović et al., 1990). The efficiency with which final energy forms are applied to provide useful energy is also about 46 percent. This results in the overall primary to useful energy conversion efficiency of 34 percent as is shown in Figure 2. In developing countries and reforming economies the overall efficiency is lower. This shows that there are large possibilities for more efficient energy use and in particular for improvement of end-use technologies. In order to assess the overall mitigation potential including efficiency improvements, an inventory of mitigation measures and related computer technology data base (CO2DB) were specifically designed at IIASA to integrate current and possible future conversion, transport, distribution and end-use systems into energy chains giving the whole bundles of technologies that define a particular reduction strategy. The first results indicate that overall energy efficiency would be nearly doubled by application of the most efficient technologies available today. The data base will serve to assess such potential with greater consistency worldwide.

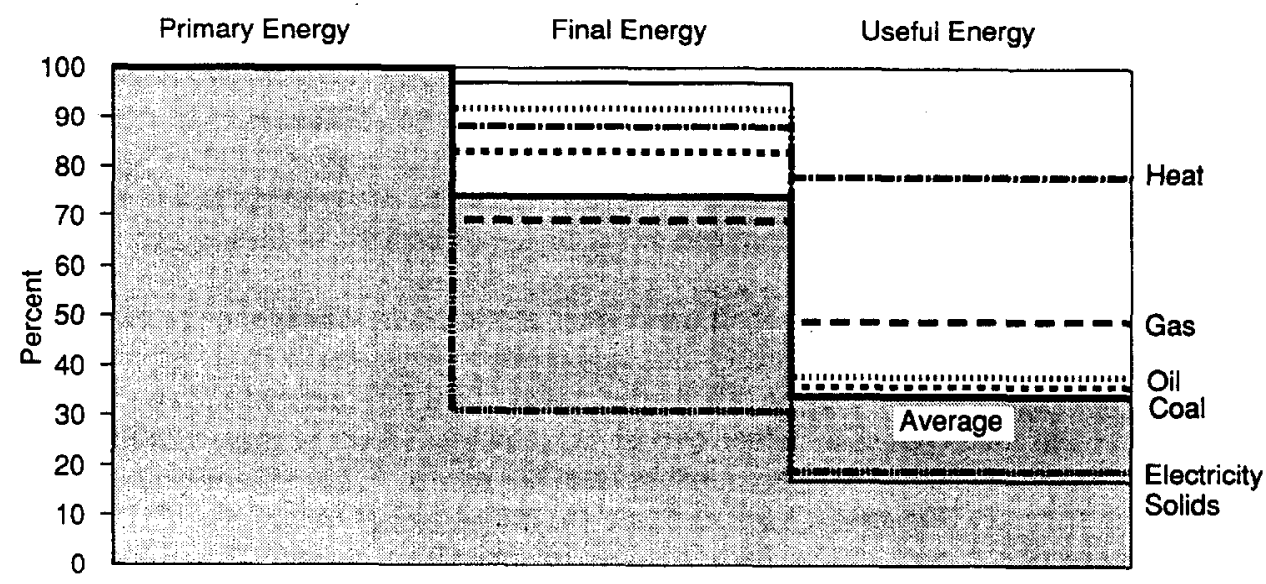

Fig. 2. Energy efficiency in the world during the late 1980s (in percent of primary energy) (Nakíenovik et al., 1990).

The rates at which such efficiency improvements can be achieved are to a large extent dependent on the vintage structure of the capital stock of our economies, rates of diffusion of new technologies and technology transfer. Figure 3 shows that the long-term improvement in energy intensity was about one percent per year in the industrialized countries. Improvement has been faster in certain areas and periods than in others. For example, over the past twenty years, aircraft manufacturers have managed to improve energy efficiency of commercial jet transports by 3 to 4 percent annually. In electricity generation, this improvement has been 2.5 to 3 percent per year over the period between 1930 and the early 1970s. These are about the upper boundary values observed over more recent history. In the long 
run there is a clear need to shift to energy sources with low carbon content such as natural gas, and ultimately to those without carbon whatsoever, such as hydro, solar, and nuclear energy, and the sustainable use of biomass. Thus, technological and economic structural change will be of fundamental importance for improvement of efficiency and lowering of carbon emissions (see Nakićenovic, 1990).

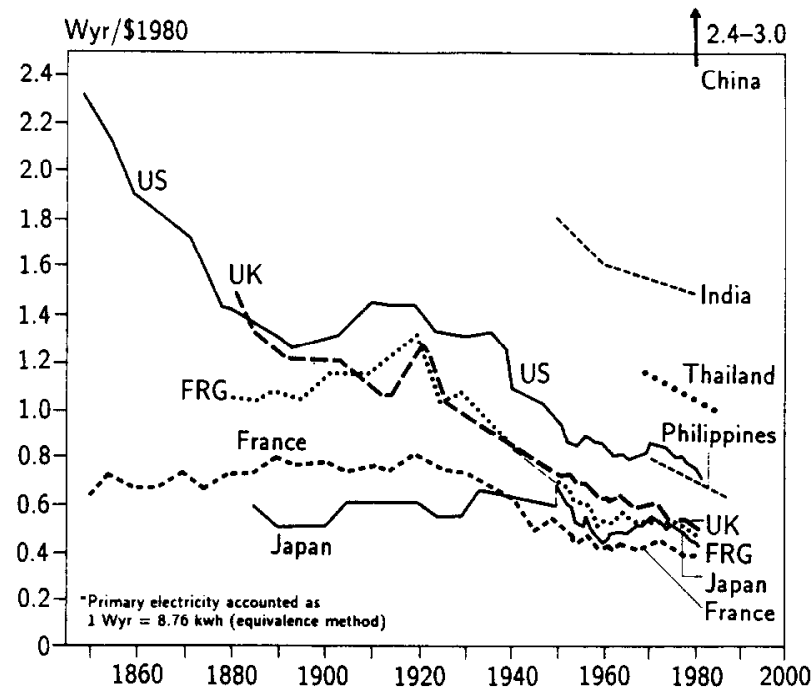

Fig. 3. Primary energy intensity (including biomass energy) per constant value added (Wyr per constant [1980] US \$) (Nakicenovic et al., 1990).

The inventory of mitigation measures and the associated technology daia base are specifically designed to provide a uniform framework for assessment of ultimate reduction potential resulting from the introduction of new technologies over different time frames and in different regions. The data base includes detailed descriptions of the technical, economic, and environmental performance of technologies as well as data pertinent to their innovation, commercialization, and diffusion characteristics and prospects. Additional data files contain literature sources and assessments of data validity and concurrent uncertainty ranges. It is an interactive software package designed to enter, update, and retrieve information on $\mathrm{CO}_{2}$ reduction and removal technologies (Messner and Strubegger, 1991).

The data base can facilitate the assessment of $\mathrm{CO}_{2}$ reduction strategies by combining many individual technologies together, i.e., to analyze measures throughout the energy chain from primary energy extraction to improvements in energy end-use efficiencies, often called full-fuel-cycle analysis. Figures 4,5 and 6 show three different options to reduce overall $\mathrm{CO}_{2}$ emissions from primary to useful energy, one from each representative end-use category: industrial motor drives, Figure 4; refrigeration, Figure 5; and passenger air transport, Figure 6. Each example compares overall energy use, $\mathrm{CO}_{2}$ emissions and costs of the respective energy chains for a number of alternative chains. They illustrate that substantial carbon dioxide reduction potentials exist with currently available technologies. The specific carbon emissions include both the direct releases from the end-use technologies themselves and all the emissions that result from the rest of the energy supply system such as energy production, import, conversion into fuels and electricity and distribution to end-use.

Final electricity is produced for motor drives and refrigeration by four different technologies: A coal fired integrated gasifier combined cycle (IGCC) and a natural gas combined cycle (NGCC) power plant, both also with $\mathrm{CO}_{2}$ recovery from the flue gases (Blok and Hendriks, 1991). Conventional jet $\mathrm{A}$ fuel originates from a refinery and oil products imports, liquid methane (LNG) is provided by a liquid natural gas chain, and liquid hydrogen by steam reforming of natural gas (Schäfer, 1991). In all cases, $\mathrm{CO}_{2}$ emissions, energy requirements and discounted costs per unit output for the whole chain are included in the analysis. Different end-use technologies considered include average vintage, the best new sold on the market and advanced, high-efficiency systems (see Johansson et al., 1989). 

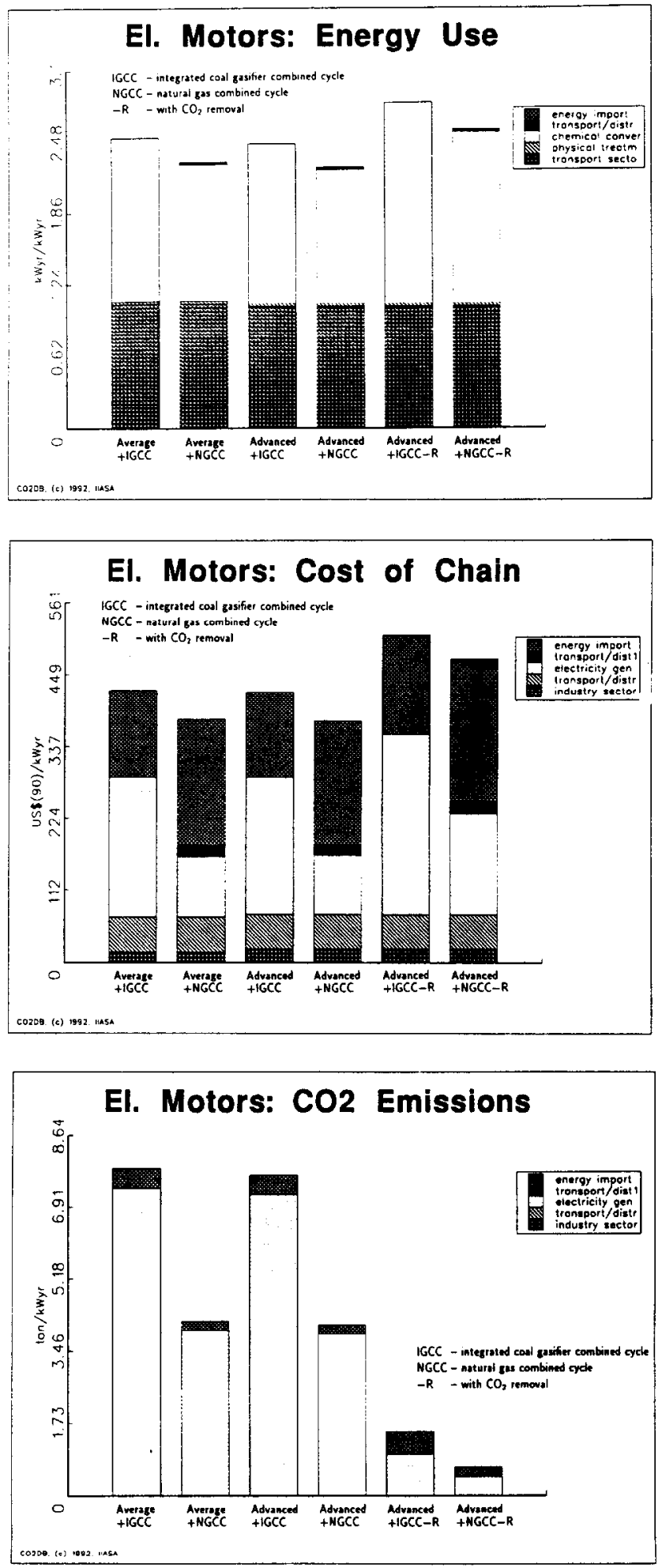

Fig. 4. Energy requirements, costs and $\mathrm{CO}_{2}$ emissions for six energy chains ending with industrial motor drives. Average and advanced motors $(112 \mathrm{~kW})$ are considered and two different power plants: An IGCC and NGCC and IGCC-R and NGCC-R with $\mathrm{CO}_{2}$ recovery. 

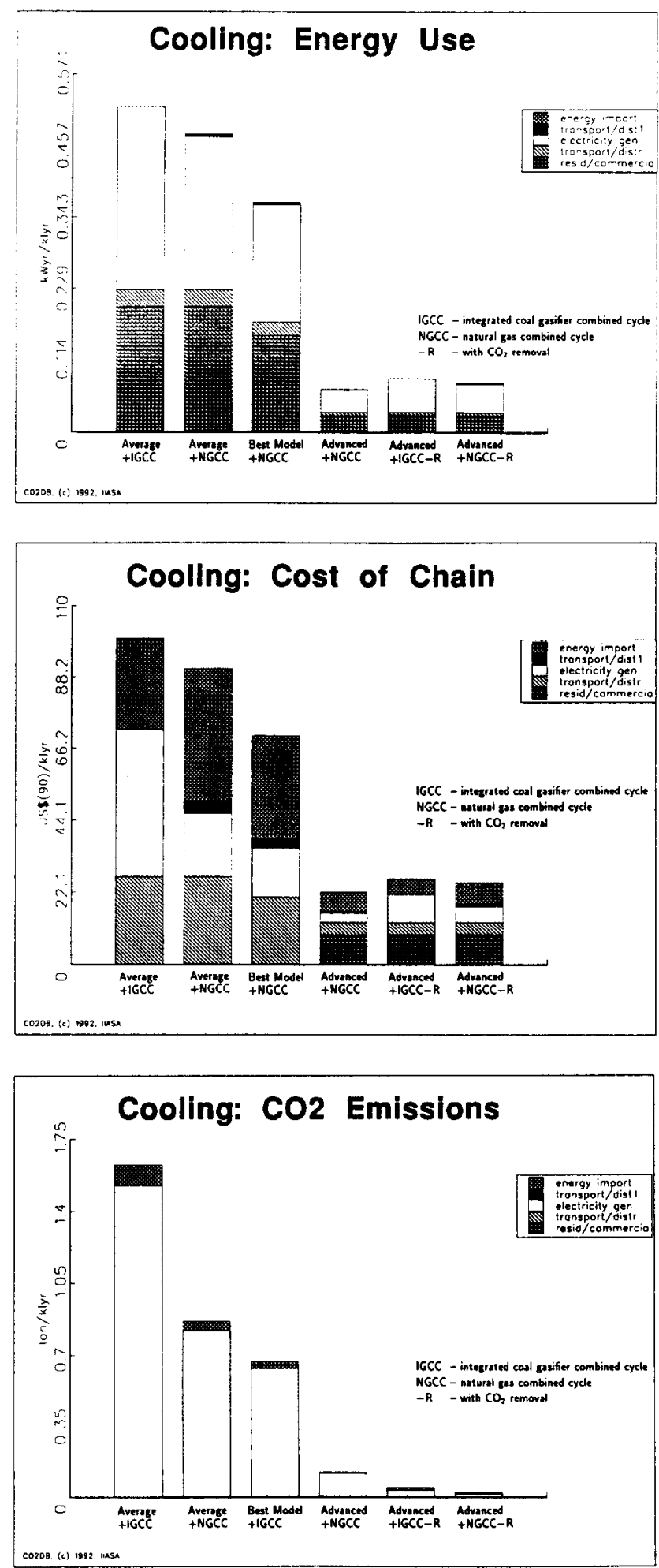

Fig. 5. Energy requirements, costs and $\mathrm{CO}_{2}$ emissions for six energy chains ending with refrigeration. Average, best new and advanced refrigerators (200 liters) are considered and two different power plants: An IGCC and NGCC and IGCC-R and NGCC-R with $\mathrm{CO}_{2}$ recovery. 

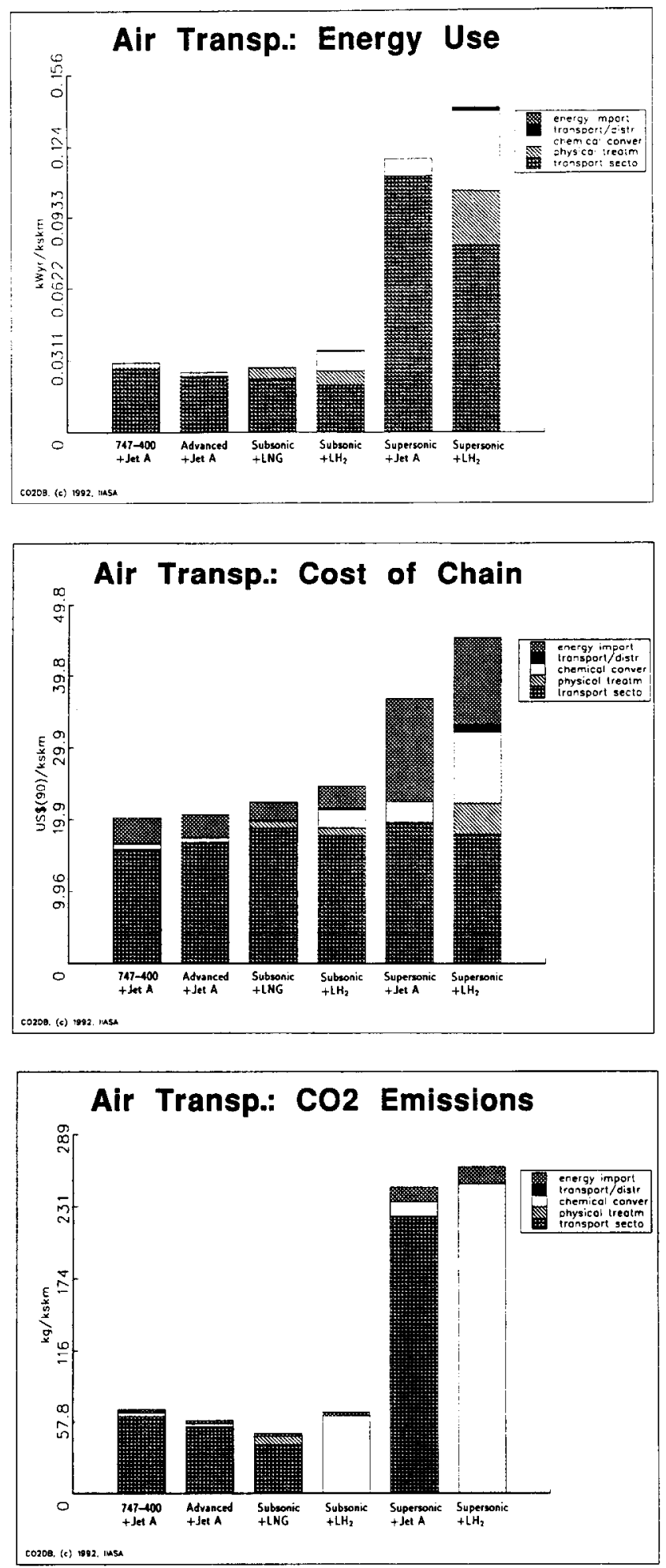

Fig. 6. Energy requirements, costs and $\mathrm{CO}_{2}$ emissions for six energy chains ending with air passenger transport. Aircraft include a Boeing 747-400 (Jet A fuel), an advanced (Jet A), a liquid methane (LNG), and a liquid hydrogen (LH2) wide-body aircraft; and Jet A and liquid hydrogen fueled supersonic aircrafts, respectively. Liquefied hydrogen is produced from natural gas. 
In the case of electric motor drives, the energy use and costs of different chains portray relatively small variations compared with $\mathrm{CO}_{2}$ emissions. Lowest energy requirements and costs are achieved with advanced motors $(112 \mathrm{~kW})$ and a NGCC power plant without $\mathrm{CO}_{2}$ recovery. The lowest emissions of $80 \mathrm{~g}$ of $\mathrm{CO}_{2}$ per $\mathrm{kWh}$ are achieved with advanced motors and $\mathrm{CO}_{2}$ recovery from NGCC power plant but with higher cost and energy requirements. In the case of refrigeration, the situation is quite different: There is a substantial variation of energy requirements, costs and emissions. A clear winner is an advanced refrigerator (all have 200 liters capacity) with NGCC power plant without $\mathrm{CO}_{2}$ recovery. In both industrial drives and refrigeration, fuel switching from coal to natural gas brings large emission reductions at moderate costs. In the case of air transport, we have a similar situation: a subsonic, methane powered aircraft has low emissions with slightly higher costs and energy requirements compared with conventional and advanced (15 percent more efficient) jet $A$ fuel and hydrogen wide-body aircraft. Supersonic transports are clearly less attractive on all accounts.

The objective of such a comparative assessment of different options and measures for reducing and removing emissions is to identify future technological systems and development paths with low specific energy requirements and low adverse environmental impacts. Progress has been achieved in improving efficiency and in decarbonizing economies, as illustrated in Figure 7. All countries shown have achieved improvements in both domains. The overall objective of this research area at IIASA is to assess the conditions that would direct the future development trajectories toward further decarbonization and energy disintensification in the world.

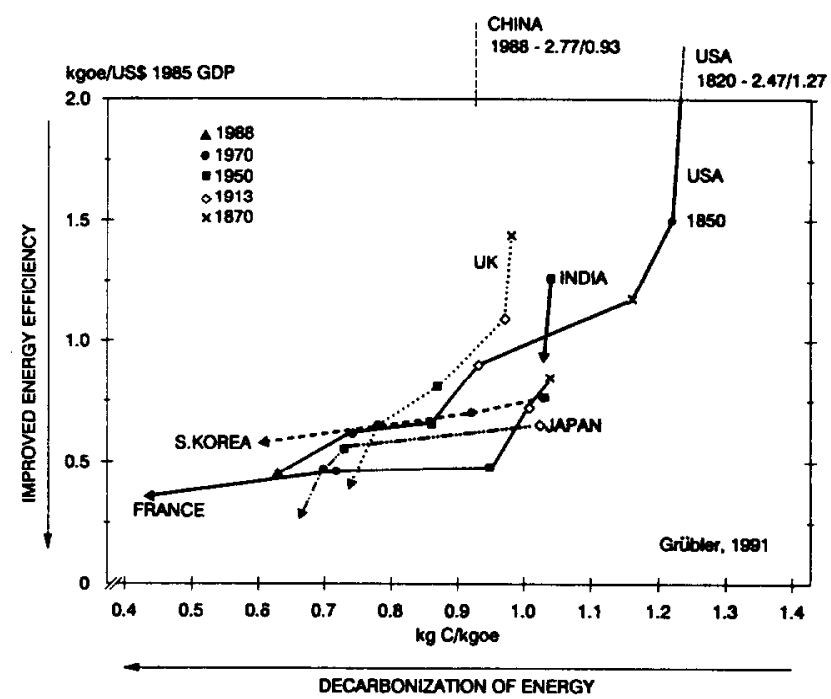

Fig. 7. Historical trends in energy (kgoe per 1000 US\$ GDP) and carbon intensity (kg C per kgoe) of various countries (Grübler and Nakicenovic, 1991).

The inventory of mitigation technologies and the $\mathrm{CO}_{2}$ data base provide a tool for assessing both the potential and relative contribution of different energy chains toward reducing $\mathrm{CO}_{2}$ emissions. The identification of best energy and cost options is easier and it also facilitates systems comparison with more comprehensive energy models. 


\section{BIBLIOGRAPHY}

Blok, K. and Hendriks, C., 1991, The Recovery and Disposal of Carbon Dioxide, Paper presented at the workshop on $\mathrm{CO}_{2}$ Reduction and Removal: Measures for Next Century, 19-21 March 1991, International Institute for Applied Systems Analysis (IIASA), Laxenburg, Austria.

Grübler, A. and Fujii, Y., 1991, Inter-generational and spatial equity issues of carbon accounts, Energy 16(11-12):1397-1416.

Grübler, A. and Nakicenovic, N., 1991, Energy and the Environment in the 21st Century, IIASA, A-2361 Laxenburg, Austria.

Johansson, J., Bodlund, B., and Williams, R., eds., 1989, Electricity, Efficient End-use and New Generation Technologies and Their Planning Implications, Lund University Press, Lund, Sweden.

Marchetti, C. and Nakicenovic, N., 1979, The Dynamics of Energy Systems and the Logistic Substitution Model, RR-79-13, IIASA, Laxenburg, Austria.

Messner, S. and Strubegger, M., 1991, Potential effects of emission taxes on $\mathrm{CO}_{2}$ emissions in the OECD and LDCs, Energy 16(11-12):1379-1395.

Messner, S. and Strubegger, M., 1991, User's Guide to CO2DB: The IIASA CO, Technology Data Bank (Version 1.0), WP-91-31a, IIASA, Laxenburg, Austria.

Nakicenovic, N., 1990, Dynamics of change and long waves, in T. Vasko, R. Ayres and L. Fontvielle, eds., Life Cycles and Long Waves, Springer Verlag, Berlin.

Nakicenovic, N., 1992, Energy Strategies for Mitigating Global Change, WP-92-1, IIASA, Laxenburg, Austria.

Nakićenovic, N. and John, A., 1991, $\mathrm{CO}_{2}$ reduction and removal: Measures for the next century, Energy 16(11-12):1347-1377.

Nakićenovic, N., Bodda, L., Grübler, A., and Gilli, P.-V., 1990, Technological Progress, Structural Change and Efficient Energy Use: Trends Worldwide and in Austria, International part of a study supported by the Österreichische Elektrizitätswirtschaft AG, IIASA, Laxenburg, Austria.

Schäfer, A., 1992, Carbon Emissions in the Passenger Transport Sector: Technology and Alternative Fuels, WP-92-04, IIASA, Laxenburg, Austria. 